\title{
Visuospatial working memory in children and adolescents with $22 q 11.2$ deletion syndrome; an fMRI study
}

\author{
Rayna Azuma • Eileen M. Daly • Linda E. Campbell • Angela F. Stevens • \\ Quinton Deeley • Vincent Giampietro • Michael J. Brammer • Beate Glaser • \\ Fiona Z. Ambery • Robin G. Morris • Steven C. R. Williams • Michael J. Owen • \\ Declan G. M. Murphy • Kieran C. Murphy
}

Received: 19 August 2008 / Accepted: 9 February 2009 /Published online: 5 March 2009

(C) Springer Science + Business Media, LLC 2009

\begin{abstract}
DS) is a genetic disorder associated with a microdeletion of chromosome $22 q 11$. In addition to high rates of neuropsychiatric disorders such as schizophrenia and attention deficit hyperactivity
\end{abstract}

This research was funded by The Healthcare Trust and the South London and Maudsley NHS Trust.

R. Azuma $(\bowtie) \cdot$ E. M. Daly $\cdot$ L. E. Campbell $\cdot$ A. F. Stevens •

Q. Deeley · F. Z. Ambery · D. G. M. Murphy

Psychological Medicine, Institute of Psychiatry,

King's College London,

Section of Brain Maturation (PO50),

DeCrespigny Park,

London SE5 8AF, UK

e-mail: r.azuma@waseda.jp

E. M. Daly

e-mail: e.daly@iop.kcl.ac.uk

L. E. Campbell

e-mail: Linda.E.Campbell@newcastle.edu.au

Q. Deeley

e-mail: q.deely@iop.kcl.ac.uk

F. Z. Ambery

e-mail: f.ambery@iop.kcl.ac.uk

D. G. M. Murphy

e-mail: d.murphy@iop.kcl.ac.uk

R. Azuma

School of International Liberal Studies,

Waseda University,

1-21-1 Nishi-Waseda, Shinjuku-ku,

Tokyo 169-0051, Japan

\section{E. Campbell}

Centre for Brain and Mental Health Research,

University of Newcastle,

Officers Quarters Complex,

James Fletcher Hospital,

Newcomen Street,

Newcastle NSW 2300, Australia disorder, children with 22q11DS have a specific neuropsychological profile with particular deficits in visuospatial and working memory. However, the neurobiological substrate underlying these deficits is poorly understood. We investi-

V. Giampietro $\cdot$ M. J. Brammer

Brain Image Analysis Unit, Institute of Psychiatry,

King's College London,

Department of Biostatistics \& Computing (PO22),

DeCrespigny Park,

London SE5 8AF, UK

V. Giampietro

e-mail: v.giampietro@iop.kcl.ac.uk

M. J. Brammer

e-mail: m.brammer@iop.kcl.ac.uk

B. Glaser · M. J. Owen

Department of Psychological Medicine, Cardiff University,

Cardiff, UK

R. G. Morris

Department of Psychology, Institute of Psychiatry,

King's College London,

PO78, DeCrespigny Park,

London SE5 8AF, UK

S. C. R. Williams

Centre for Nueroimaging Sciences, Institute of Psychiatry,

King's College London,

Section of Brain Maturation (PO89), DeCrespigny Park,

London SE5 8AF, UK

e-mail: steven.williams@iop.kcl.ac.uk

K. C. Murphy

Department of Psychiatry,

Royal College of Surgeons in Ireland,

Beaumont Hospital,

Dublin, Ireland

e-mail: KMurphy@rcsi.ie 
gated brain function during a visuospatial working memory (SWM) task in eight children with 22q11DS and 13 healthy controls, using fMRI. Both groups showed task-related activation in dorsolateral prefrontal cortex (DLPFC) and bilateral parietal association cortices. Controls activated parietal and occipital regions significantly more than those with 22q11DS but there was no significant between-group difference in DLPFC. In addition, while controls had a significant age-related increase in the activation of posterior brain regions and an age-related decrease in anterior regions, the 22q11DS children showed the opposite pattern. Genetically determined differences in the development of specific brain systems may underpin the cognitive deficits in 22q11DS, and may contribute to the later development of neuropsychiatric disorders.

Keywords Velo-cardio-facial syndrome .

22q11.2 deletion syndrome - Spatial working memory fMRI $\cdot$ Ageing $\cdot$ Schizophrenia

\section{Introduction}

22q11.2 deletion syndrome (22q11DS), also known as velo-cardio-facial syndrome (VCFS) is a genetic disorder associated with a microdeletion in chromosome 22q11.2 [1]. While the physical phenotype is variable, commonly reported features include characteristic dysmorphology, congenital heart disease and cleft palate [2, 3]. A characteristic behavioural phenotype in 22q11DS has also been described with high rates of schizophrenia and attention deficit / hyperactivity disorder (ADHD) [4-7]. In addition, children and adults with 22q11DS typically have mild learning disabilities and a specific cognitive profile with particular deficits of visuospatial function, working memory, attention, executive function [8-13].

There is increasing evidence for a robust association between 22q11DS and schizophrenia [14]. Indeed, deletion of chromosome 22q11 represents the most commonly known risk factor for the development of schizophrenia and offers a unique model for identifying the neurobiological substrate underlying the development of psychotic disorders. In the general population, people with schizophrenia have deficits in a number of cognitive domains, including visuospatial working memory (SWM) [15-26]. Furthermore, recent neuropsychological and neuroimaging studies indicate that those at high-risk of developing psychosis also show deficits in SWM [15, 27-31]. For instance, Saperstein and colleagues compared the relative risk ratios for SWM deficits among 23 schizophrenics, 17 relatives of patients with schizophrenia with schizophrenia spectrum personality disorders (SSPD), 23 non-SSPD relatives of patients with schizophrenia, 14 SSPD commu- nity members with no family history of psychosis, and 36 healthy community controls [27]. Relative risk of SWM deficits, as compared with healthy community controls, increased with the relative genetic liability, where it was highest among patients with schizophrenia, second highest among SSPD family members, then family non-SSPD and community SSPD. The authors suggested that the pattern of SWM performance deficits reflected the proposed model of latent genetic liability, upholding SWM as a viable cognitive endophenotype [27]. Similarly, 22q11DS adults with schizophrenia are significantly more impaired in a number of cognitive domains, including spatial working memory (SWM), as compared to those without schizophrenia [12].

The neural basis for SWM has been investigated in many neuroimaging studies within the general population. These reported that SWM tasks activate a cortical pathway extending bilaterally from prefrontal cortex (more dorsal than ventral for spatial rather than object working memory) to anterior cingulate and parietal regions. This is true in both children and adults [32-35]. Furthermore, relatively few studies that have also examined the developmental changes in brain functions during normal brain development reported that there may be an age-related increase in brain activations in frontal and parietal cortical areas [32, 33, 36], which is consistent with developmental changes in the brain structure [37].

Frontal cortex may be functionally different in people with schizophrenia. For example, many neuroimaging studies on working memory processing in schizophrenia report aberrant activation of prefrontal cortex although changes have not always been consistent [20, 25, 38-43]. In addition, a recent fMRI study of brain function during a memory-guided saccade SWM task in the offspring of people with schizophrenia (i.e. a 'High Risk' group) reported that they also had significantly reduced activation of the DLPFC and parietal cortex as compared to controls [29]. Thus, there is preliminary evidence that abnormalities in the function of frontal, and perhaps parietal, cortex during SWM tasks may precede the onset of schizophrenia.

We, and others, previously reported that people with 22q11DS have neurodevelopmental abnormalities in the anatomy of frontal and parietal regions [44-48] and possibly a disruption in the connectivity of the frontalparietal pathway $[49,50]$. As noted above, in the general population, aberrant activation of these brain regions during SWM has been reported in people at risk of developing psychosis [29]. However, to date nobody has examined brain function during a SWM task in people with 22q11DS, or examined if the functional developmental trajectory of these regions is different. Thus, we (1) investigated the neural functioning in children and adolescents with 22q11DS and healthy controls during a SWM task, and (2) carried out a preliminary analysis of age-related differences in brain function. 


\section{Methods}

Subjects

We included 21 volunteers who could reliably carry out the SWM task (eight subjects with 22q11DS and 13 healthy controls). All were right-handed. The 22q11DS group comprised four males and four females, aged 9-16 years and the healthy controls included eight males and five females, aged 8-17 years (see Table 1 for demographic data). Where possible we used sibling-controls (eight out of 13) in order to match as best we could for socioeconomic factors. The sibling and non-sibling controls did not significantly differ in FSIQ $(F<1)$.

The 22q11DS volunteers were recruited through the 22q11 (UK) Support group and the Behavioural Genetics Clinic at the Maudsley Hospital/Institute of Psychiatry, Kings College London. 22q11DS was diagnosed by fluorescence in-situ hybridisation (FISH) using the N25 probe (Oncor Inc). Eight of the control group were siblings, and five were recruited from the local community. All the participants, and/or their parents gave written informed consent/assent as approved by the local research ethics committee (Institute of Psychiatry, South London and Maudsley Trust).

All subjects underwent routine psychiatric and physical examination, and routine blood tests. Overall cognitive ability was measured using the Wechsler Intelligence Scale for Children-III (WISC-III) [51]. We excluded people with a clinically detectable co-morbid psychiatric disorder or physical disorder affecting brain function (e.g. ADHD, hypothyroidism, or epilepsy), or with a clinically abnormal MRI scan - as determined by a neuroradiologist. As expected controls had significantly

Table 1 Profiles of subjects for each group

\begin{tabular}{lll}
\hline Variables & $\begin{array}{l}22 \mathrm{q} 11 \mathrm{DS} \\
n=8\end{array}$ & $\begin{array}{l}\text { Control } \\
n=13(8)\end{array}$ \\
\hline Age range (mean \pm SD) & $9-16(12 \pm 2)$ & $8-17(13 \pm 3)$ \\
Sex: M/F & $4 / 4$ & $8(4) / 5(4)$ \\
Performance IQ & $67 \pm 7$ & $109 \pm 20$ \\
Verbal IQ & $71 \pm 15$ & $110 \pm 17$ \\
FSIQ & $67 \pm 8$ & $114 \pm 17$ \\
COMT genotype & & \\
Val & 5 & 0 \\
Met & 3 & 0 \\
Val/Val & 0 & 2 \\
Val/Met & 0 & 4 \\
Met/Met & 0 & 1 \\
Unknown & 0 & 6 \\
\hline
\end{tabular}

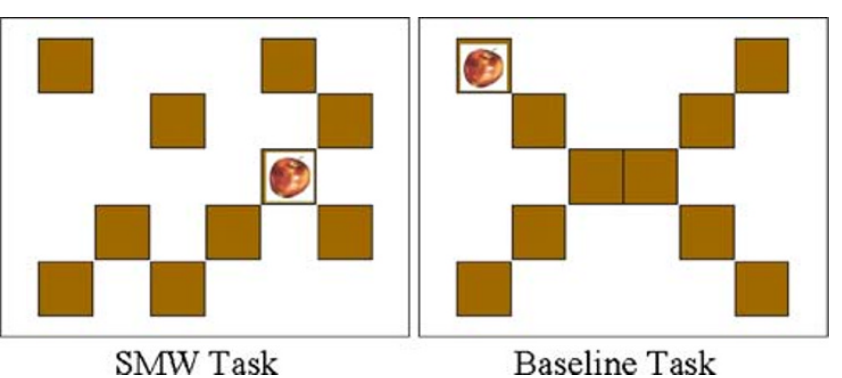

Fig. 1 Examples of stimuli used for the SWM task and baseline task

higher scores for performance IQ (PIQ), verbal IQ (VIQ), and full scale IQ (FSIQ) $(\mathrm{p}<.001)$. All were drug free at the time of testing.

Tasks

We used a Spatial Working Memory (SWM) 'blockdesign' task, based on one developed by Klingberg et al. [32]. In our version, ten brown, square boxes (see Fig. 1) in random positions, instead of the original $4 \times 4$ matrix, were used as possible target locations in order to minimize the possibility of giving verbal labels for each location. The locations of the boxes were changed from trial to trial.

Each trial began with the presentation of ten boxes for $500 \mathrm{~ms}$ to indicate the possible target locations for the trial. A picture of an apple (target) appeared sequentially in some of these boxes for $1,000 \mathrm{~ms}$. Either three or five of the boxes per trial were used as target locations, creating two conditions (Fig. 2). The gaps between the presentations of the target locations were 2,000 and $500 \mathrm{~ms}$ respectively for the three and five apple conditions. This kept the overall presentation time constant at 7,000 ms. After 2,000 ms following the last target location, one of the boxes went blue for another 2,000 ms. The subjects had to press one of the two buttons to indicate whether or not this box was a target location during this period. Then, the screen became blank for 1,000 before the next trial began. Half the subjects were instructed to press the left button if the blue box was in one of the target locations and the right button for the non-target locations. For the other subjects, the response-to-button mapping was reversed. For button responses, the subjects used a rectangular box $(6 \times 11 \mathrm{~cm})$ where two square buttons $\left(1 \mathrm{~cm}^{2}\right)$ were placed in the middle with a gap of about $2.5 \mathrm{~cm}$. They were instructed to hold the box with their left hand and press the buttons with their right index and middle fingers.

There was also a baseline task in which the boxes were arranged in the shape of an " $X$ " (see Fig. 1), with the target locations appearing in the four corner boxes in a predictable order. Subjects were instructed to look at the 


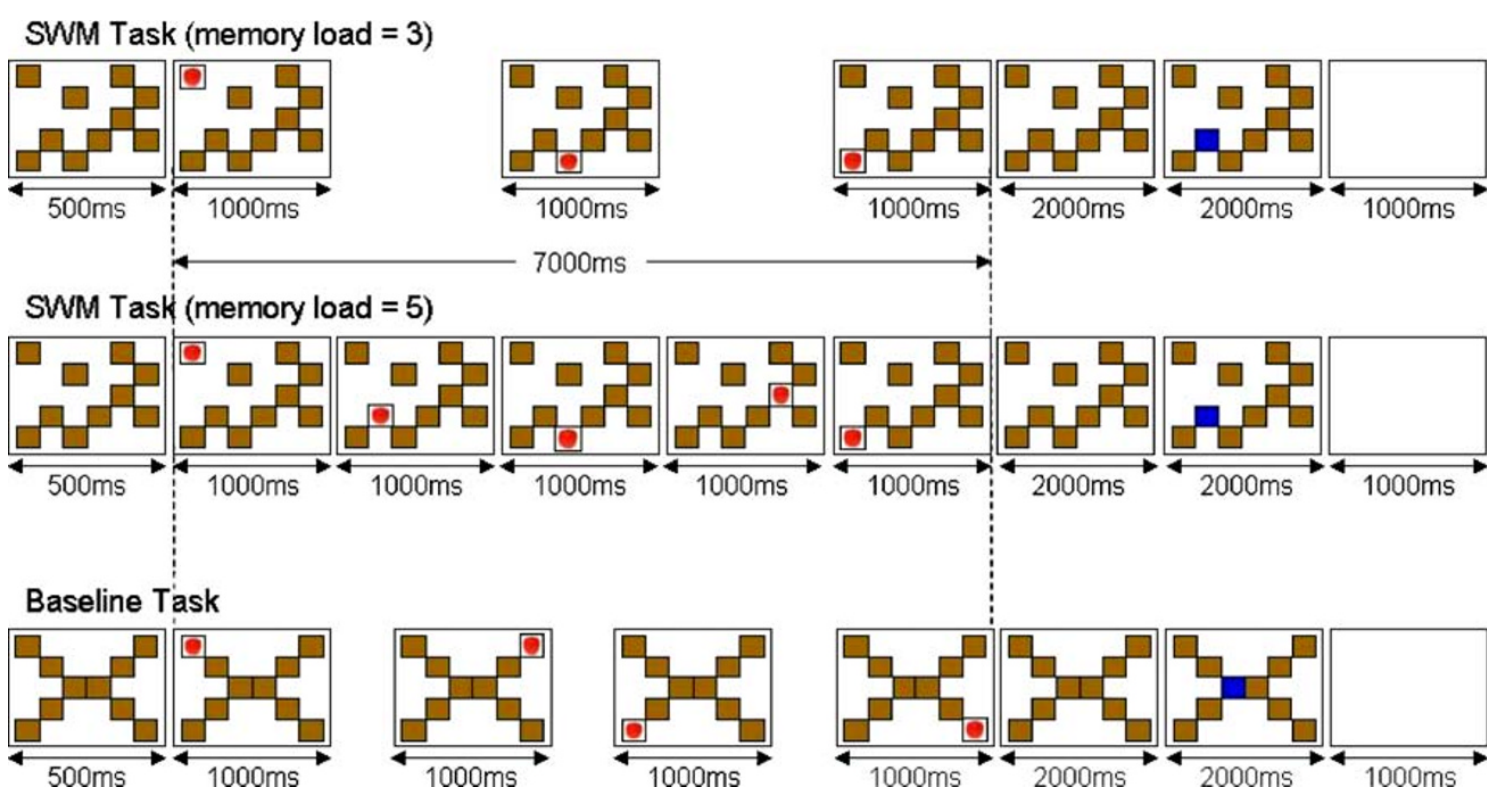

Fig. 2 SWM task performed during the fMRI scan. For the SWM task (top two), subjects had to remember the positions of the boxes in which an apple (target) was presented sequentially. After 2,000 ms of delay following the presentation of the target in the final box for a given trial, one of the boxes was highlighted, and the subjects pressed a button to indicate whether or not the target had appeared in this box.

target as it appears in different locations, and then press a pre-specified button when one of the boxes in the middle was highlighted in blue. This way, both tasks had the components of visual stimulation, eye movements and motor output, while the SWM task had an extra component of SWM.

There were two runs of ten blocks each where the subjects alternated between the baseline block and SWM block (10 blocks $\times$ baseline; 5 blocks $\times$ swm 3 ; 5 blocks $\times$ swm5 in total). There were three trials of the same condition (i.e. baseline, swm3, swm5) in each block, and a brief message at the beginning of each block indicated whether it was to be a baseline block or a SWM block. The two conditions of the SWM task (i.e. three-targets or five targets) were distributed in pseudo-random order.

\section{Practice}

Prior to the scan, all the subjects completed an offline version of the SWM task to practise the task. The subjects were first given a block of ten SWM trials with just two target locations. This was repeated until the subjects could respond with an accuracy rate of more than $80 \%$. Then, the subjects completed the eight blocks of ten SWM trials. The number of target locations for each block increased from two to eight. The target stimuli were presented at the fixed rate of 1,000 ms presentation time and 1,000 ms interval. For each trial, an auditory feedback (a high or low tone)
For the "memory load=3" condition, the target was presented in three of the ten boxes, whereas for the "memory load $=5$ " condition, five boxes were used target locations. For the baseline task (bottom), the stimuli were presented sequentially in the predictable order (i.e. topleft, top-right, bottom-left, bottom-right). When the middle box was highlighted after the delay, subjects pressed the pre-specified button

was given to indicate whether or not the response made was correct. After completing the offline task, the subjects were given four blocks of the scanning version of the task to get familiarised with the setting.

Image acquisition

All functional imaging data were acquired at $1.5 \mathrm{~T}$ using a GE, Neuro-optimised MR System (General Electric Healthcare, Milwaukee, WI) based at the Maudsley Hospital, London. A quadrature birdcage headcoil was used for radio frequency transmission and reception. An inversion recovery echoplanar imaging (EPI) dataset was acquired at 43 near-axial $3 \mathrm{~mm}$ thick planes parallel to the anterior commissure-posterior commissure (AC-PC) line: time-toecho (TE) $73 \mathrm{~ms}$, inversion time (TI) $180 \mathrm{~ms}$, repetition time (TR) $16 \mathrm{~s}$, in-plane resolution $1.72 \mathrm{~mm}$, interslice gap $0.3 \mathrm{~mm}$, matrix size: $128 \times 128$ pixels. This higher resolution EPI dataset provided whole brain coverage and was later used to register the fMRI datasets acquired from each individual in standard stereotactic space. 16 near-axial noncontiguous slices (7-mm thick, $0.7-\mathrm{mm}$ slice skip) were prescribed parallel to the anterior commissure-posterior commissure (AC-PC) line and covering the whole brain: TE $40 \mathrm{~ms}$, TR $2 \mathrm{~s}$, in-plane resolution $3.44 \mathrm{~mm}$, interslice gap $.7 \mathrm{~mm}$, matrix size: $64 \times 64$ pixels.

For each experimental series, $220 \mathrm{~T} 2 *$-weighted, echoplanar images depicting Blood Oxygenation Level Depen- 
dent (BOLD) contrast [52] were collected from each slice at an echo time (TE) of $40 \mathrm{~ms}$ and a repetition time (TR) of $2 \mathrm{~s}$. Four dummy acquisitions were acquired at the beginning of each series to ensure that the spin system had reached steady state and the chosen flip angle was $70^{\circ}$ and number of averages $(\mathrm{NEX})=1$.

Visual Stimuli were presented via a conventional PC and LCD projector system to a screen placed at the feet of the subject and overt responses were made using an MR compatible two-button box placed in the subject's dominant right hand. Presentation of all stimuli and recording of all subject responses were synchronised to the imaging system. The total functional image acquisition time for each series was $7 \mathrm{~min} 28 \mathrm{~s}$.

\section{Neuroimaging data analysis}

\section{Individual brain activation maps}

Data were analysed using a non-parametric approach with XBAM, the local software developed at the Institute of Psychiatry [53]. The images were first processed to minimize motion related artefacts [54]. They were then smoothed using a Gaussian filter (FWHM $7.2 \mathrm{~mm}$ ) to improve the signal to noise characteristics of the images.

Responses to the experimental paradigms were then detected by first convolving each component of the experimental design with each of two gamma variate functions (peak responses at 4 and $8 \mathrm{~s}$ respectively). The best fit between the weighted sum of these convolutions and the time series at each voxel was computed using the constrained BOLD effect model suggested by Friman et al. [55]. A goodness of fit statistic was computed, consisting of the ratio of the sum of squares of deviations from the mean image intensity (over the whole time series) due to the model to the sum of squares of deviations due to the residuals (SSQratio).

The data were then permuted by the wavelet-based method described and extensively characterized in Bullmore et al. [56]. Using this distribution, it is possible to calculate the critical value of SSQratio needed to threshold the maps at any desired type I error rate. The detection of activated voxels is extended from voxel to cluster level using the method described in detail by Bullmore et al. [57].

\section{Group brain activation maps}

The observed and randomised data for each individual are transformed into the standard Talairach space [58] using the procedure described in detail in Brammer et al. [53]. Group activation maps are then computed by determining the median SSQratio at each voxel (over all individuals) in the observed and permuted data maps (medians are used to minimize outlier effects). Analysis was extended from voxel to cluster level by the permutation method described by Bullmore et al. [57] and the expectation false positive clusters set to $<1$ per brain.

\section{Between group analysis}

Group differences were estimated on a voxel-wise basis across the whole brain by fitting a regression model of the type

$y=a+b X+e$

to the data at each voxel. In this formulation, $\boldsymbol{y}$ represents a vector of individual subject SSQratios at each voxel in standard space, $\mathbf{X}$ is a group contrast matrix and $\boldsymbol{e}$ is a vector of residual errors at each voxel. The estimate of the parameter $b$ describes the magnitude of the group difference. The significance of these estimates of $b$ is determined by permutation as follows. The elements of the contrast matrix $\mathbf{X}$ are permuted to give a random assignment of subjects to each group and the model refitted. Repeating this procedure a large number of times at each voxel and subsequently combining the estimates of $b$ over all voxels produces the distribution of $b$ under the null hypothesis of no effect of group membership on activation. Observed values of $b$ in the unpermuted data can then be tested against this distribution to assess their probability under the null hypothesis. This analysis is also extended to the cluster level as previously described (Bullmore et al. [54]).

\section{Correlations of age and brain activities}

We also conducted a correlation analysis to examine agerelated differences in brain functions associated with SWM in 22 q11DS and controls, then contrasted the trajectories between the groups. Correlational analysis is carried out by computing the Pearson product-moment correlation coefficient at every voxel between the subject ages and statistical values (SSQ ratios). The significance of this correlation at whole brain level is determined by permuting the order of subjects 50 times at each voxel and re-determining the correlation coefficient. Combining the correlation coefficients following permutation over the whole brain gives us the null distribution of correlation coefficients. The significance of the observed (pre-permutation) correlation coefficients is then determined at voxel and cluster level using the data-driven null distribution produced as described above.

\section{Group comparison of age correlations}

In order to compare the age-correlation (i.e. developmental differences) between the groups, the Pearson productmoment correlation coefficient was calculated for each 
group independently and the difference between the correlation coefficients was then computed. To test the significance of this difference, the behavioural data were randomly permuted between the two groups and the above calculation procedure repeated. The permutation/calculation procedure was repeated 50 times at each voxel and the resulting data combined over all voxels to form a "global" distribution of correlation coefficient differences under the null hypothesis of no difference between the correlation between behaviour and BOLD response in the two groups. The significance of any observed difference in correlation in the original data could then be assessed by reference to this distribution.

\section{Results}

Task performance

For each subject, task performance was assessed as the percentage of correct responses for the SWM task. Since the accuracy levels for the SWM tasks and the baseline task did not significantly differ between the sibling and nonsibling controls, and neither of them have a deletion in 22q11.2, data from both sibling and non-sibling healthy children have been analysed together as the healthy control group. The task performance for the 22q11DS group was $73( \pm 16) \%$ and $79( \pm 12) \%$ for the target $=3$ and target $=5$ conditions, respectively, whereas, these were $88( \pm 10) \%$ and $88( \pm 10) \%$ in the healthy control group. The accuracy level for the baseline task was $97( \pm 5) \%$ for the $22 \mathrm{q} 11 \mathrm{DS}$ group and $96( \pm 6) \%$ for the control group. An analysis of variance (ANOVA) (group $\times$ task type) on the accuracy revealed there was a significant main effect of group $(F(1,57)=8.0$, $p<0.01)$; the main effect of task type $(F(2,57)=13.2$, $p<0.001)$; but the interaction was not significant $(F(2,57)=$ $2.9, p=0.06)$. The main effect of group indicated that the overall performance accuracy was significantly higher in the controls. A post-hoc analysis suggested that in both groups the accuracy rates for the baseline task was higher than those for the SWM tasks. There was no significant effect of memory load (swm3 and swm5) on performance accuracy.

Image data analysis

Since there was no difference in brain activations between the target $=3$ and target $=5$ conditions data from the two conditions were combined in order to increase statistical power. An averaged activation map image (voxel $p=0.05$; cluster $p=0.01$ ) was created for each group (see Fig. 3). At this level of stringency there was less than one false positive cluster for each analysis. Table 2 shows the areas

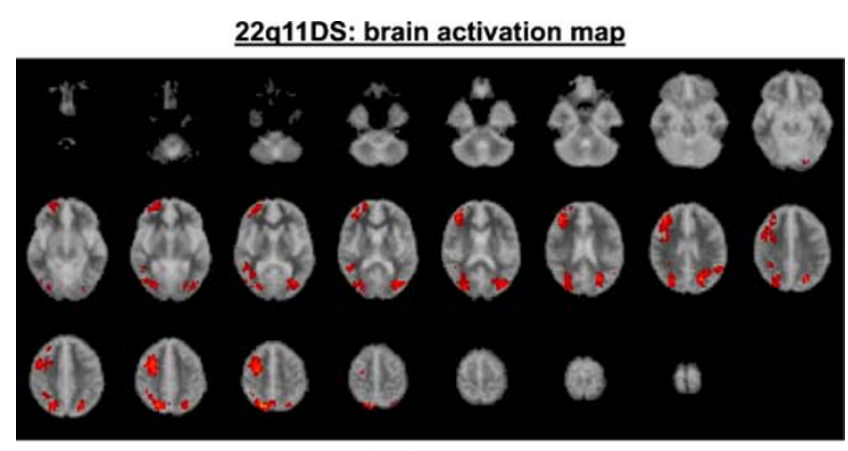

Controls: brain activation map

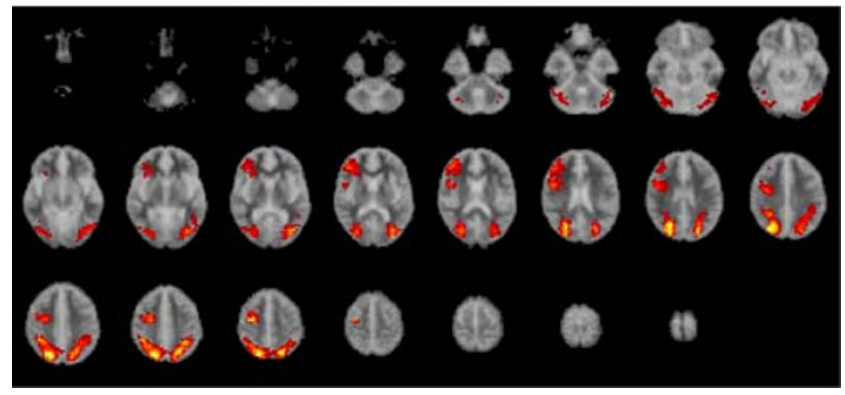

Fig. 3 Brain activation maps for the 22q11DS group (above) and the control group (below). The red/yellow areas indicate regions where there was significant activation during the SWM task as compared to the baseline task (voxel $p=0.05$, cluster $p=0.01$ )

activated significantly more during the SWM task than during the baseline task for each group.

\section{Group comparison}

Both groups significantly activated brain regions normally associated with SWM processes, such as, DLPFC, parietal regions, as well as primary visual regions in the occipital lobule (Fig. 4 and Table 3). We compared group activation using an analysis of variance (voxel $p=0.01$; cluster $p=$ 0.01 ) on the "SWM activation-baseline activation" data. At this level of stringency there was less than one false positive cluster for analysis. Controls had significantly greater activation than people with 22q11DS (Table 3) bilaterally in precuneus (BA 7, 31), and right cuneus (BA 18). In order to see if differences in parietal activation could have been related to significant differences in task performance, we have carried out correlation analysis between task performance accuracy and brain activities. (see Fig. 4). Significantly positive correlation between task performance and parietal activities was found in the left precuneus (BA 7) in the $22 q 11 \mathrm{DS}$ group but absent in the controls. In contrast, significantly negative correlations was found in the left inferior parietal lobule (BA 40) in the controls. Thus, it was unlikely that the significant group differences in the parietal region were attributable to higher performance in the controls. Indeed, the overall pattern of group differences remained even when we re-ran the same 
Table 2 Brain regions where the clusters of more than five voxels were activated during the SWM task for each subject groups (voxel $p=0.05$, cluster $p=0.01$ )

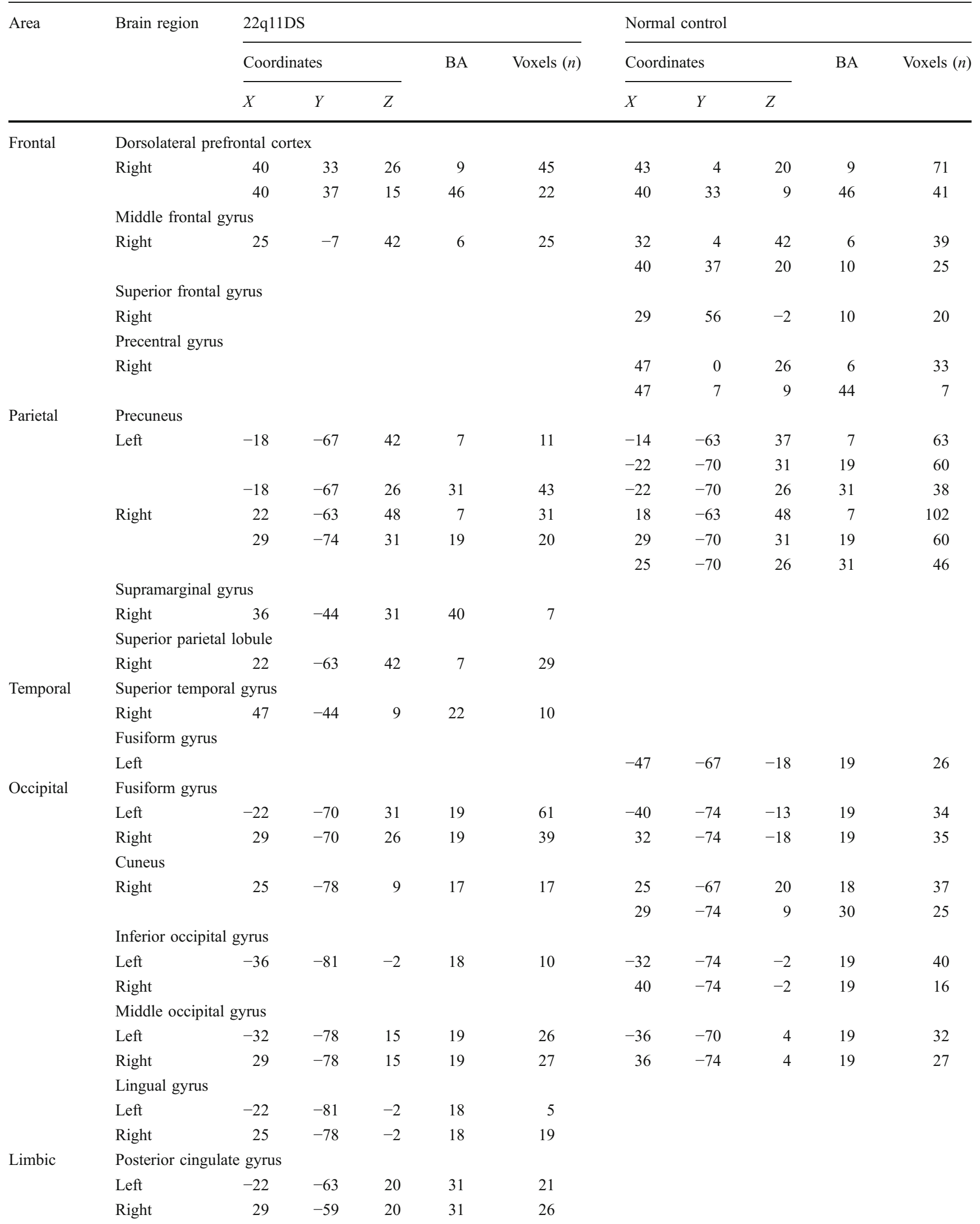


Table 2 (continued)

\begin{tabular}{|c|c|c|c|c|c|c|c|c|c|c|c|}
\hline \multirow[t]{3}{*}{ Area } & \multirow[t]{3}{*}{ Brain region } & \multicolumn{5}{|c|}{$22 q 11 D S$} & \multicolumn{5}{|c|}{ Normal control } \\
\hline & & \multicolumn{3}{|c|}{ Coordinates } & \multirow[t]{2}{*}{ BA } & \multirow[t]{2}{*}{ Voxels $(n)$} & \multicolumn{3}{|c|}{ Coordinates } & \multirow[t]{2}{*}{ BA } & \multirow[t]{2}{*}{ Voxels ( $n$} \\
\hline & & $X$ & $Y$ & $Z$ & & & $X$ & $Y$ & $Z$ & & \\
\hline & \multicolumn{11}{|l|}{ Insula } \\
\hline & \multirow[t]{2}{*}{ Right } & & & & & & 29 & 26 & -2 & 13 & 19 \\
\hline & & & & & & & 47 & 7 & 15 & 13 & 15 \\
\hline
\end{tabular}

analysis, and covaried for task accuracy. The 22q11DS group did not have significantly greater activation than controls in any brain region. Contrary to our expectation, there was no significant between-group difference in activation of DLPFC.

Age correlation

Increased activation with age In the 22q11DS group (voxel $p=0.005$; cluster $p=0.01$; false positive cluster $<1$ ) there was a significant age-related increase in the left VLPFC (BA 47), superior frontal gyrus (BA 6), middle occipital gyrus (BA 18), and right precuneus (BA 7) (Fig. 5 and Tables 4 and 5). In contrast the healthy control group had a significant age-related increase in bilateral superior parietal lobule (BA 7), left precuneus (BA 7), inferior parietal lobule (BA 40), fusiform gyrus (BA 37), inferior temporal gyrus (BA 20), middle-inferior occipital gyrus (BA 19), posterior cingulate gyrus (BA 31), right middle frontal gyrus (BA 10), and angular gyrus (BA 39). (see Fig. 4 and Table 4).

Decreased activation with age There was also a significant negative correlation (voxel $p=0.005$; cluster $p=0.01$; false positive cluster $<1$ ) between age and decreased brain activations. For the healthy controls, most of the agerelated decrease was observed in frontal areas (e.g. bilateral VLPFC, middle frontal gyri, left DLPFC, and right precentral gyrus). In contrast, the 22q11DS group showed an age-related decrease mostly in non-frontal areas, such as bilateral parietal regions, fusiform gyri, cingulate gyri, right temporal regions and parahippocampal gyrus. (see Fig. 4 and Table 5).

Group differences in age effect There were significant differences between the 22q11DS and control groups in the developmental trajectories of brain activations for SWM (see Table 6).
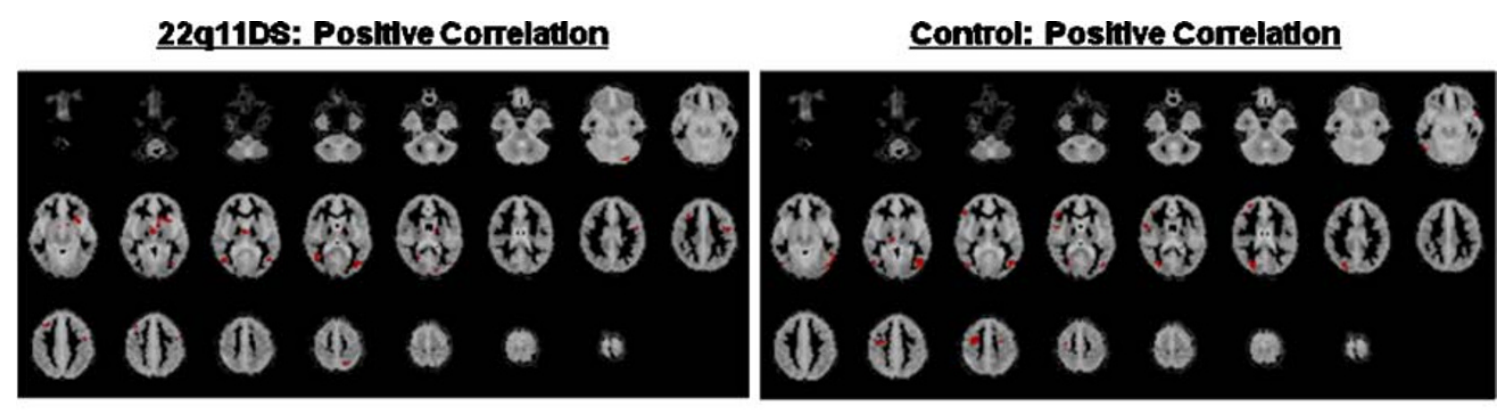

22q11DS: Negative Correlation

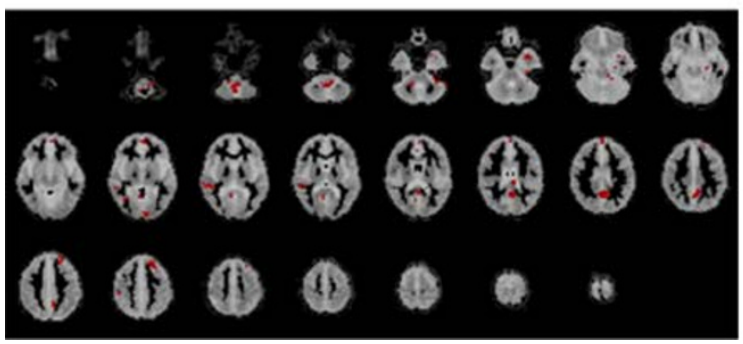

Control: Negattve Correlation

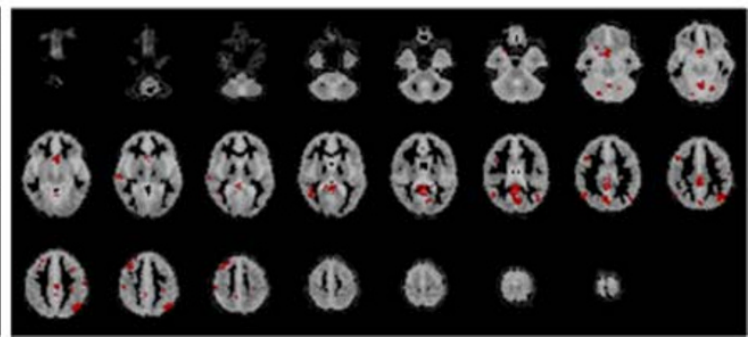

Fig. 4 Areas that showed significant correlation between task performance and brain activations were observed (voxel $p=0.05$, cluster $p=0.01$ ) 
Table 3 Brain regions where larger activations were observed for the control group than for the 22q11DS group (voxel $p=0.01$, cluster $p=0.01$ )

\begin{tabular}{|c|c|c|c|c|c|c|c|c|c|c|c|}
\hline \multirow[t]{3}{*}{ Area } & \multirow[t]{3}{*}{ Brain region } & \multicolumn{5}{|c|}{ Control $>$ VCFS } & \multicolumn{5}{|c|}{ Control > VCFS (covariated) } \\
\hline & & \multicolumn{3}{|c|}{ Coordinates } & \multirow[t]{2}{*}{ BA } & \multirow[t]{2}{*}{ Voxels $(n)$} & \multicolumn{3}{|c|}{ Coordinates } & \multirow[t]{2}{*}{ BA } & \multirow[t]{2}{*}{ Voxels $(n)$} \\
\hline & & $X$ & $Y$ & $Z$ & & & $X$ & $Y$ & $Z$ & & \\
\hline \multirow[t]{5}{*}{ Parietal } & \multicolumn{11}{|l|}{ Precuneus } \\
\hline & Right & 22 & -67 & 37 & 7 & 44 & 22 & -63 & 37 & 7 & 48 \\
\hline & Left & -29 & -44 & 42 & 7 & 37 & -29 & -44 & 42 & 7 & 45 \\
\hline & \multicolumn{11}{|c|}{ Superior parietal lobule } \\
\hline & Right & & & & & & 22 & -67 & 42 & 7 & 43 \\
\hline \multirow[t]{5}{*}{ Occipital } & Cuneus & & & & & & & & & & \\
\hline & Right & 25 & -67 & 20 & 18 & 18 & 25 & -78 & 20 & 18 & 17 \\
\hline & Precuneus & & & & & & & & & & \\
\hline & Right & 25 & -74 & 15 & 31 & 9 & & & & & \\
\hline & Left & -25 & -70 & 20 & 31 & 5 & & & & & \\
\hline \multirow[t]{2}{*}{ Limbic } & \multicolumn{11}{|l|}{ Cingulate gyrus } \\
\hline & Right & & & & & & 29 & -70 & 15 & 30 & 7 \\
\hline
\end{tabular}

Minimum cluster size $=5$ voxels

Overall, the controls showed significantly larger age-related changes in brain activations (both increase and decrease) than 22q11DS in widespread cortical and subcortical regions, predominantly in the right hemisphere (e.g. middle frontal gyrus (BA 25), inferior parietal lobule (BA 40), superior temporal gyrus (BA 42), parahippocampal gyrus (BA 36), hippocampus, caudate, and brain stem), as well as bilateral inferior frontal gyrus (BA11), and left thalamus and cerebellum. The 22q11DS group, in contrast, showed larger correlational changes than the controls in the left inferior frontal gyrus (BA 44), and caudate only.

\section{Discussion}

We investigated brain function during a SWM task in children and adolescents with 22q11DS, and healthy controls. Both groups showed activation of the DLPFC, parietal and occipital regions during performance of the visual SWM task. However, healthy controls had significantly greater activation than children with 22q11DS, in parietal and occipital regions with no significant difference in activation of frontal regions between both groups.

\section{DS: Age-related increase}

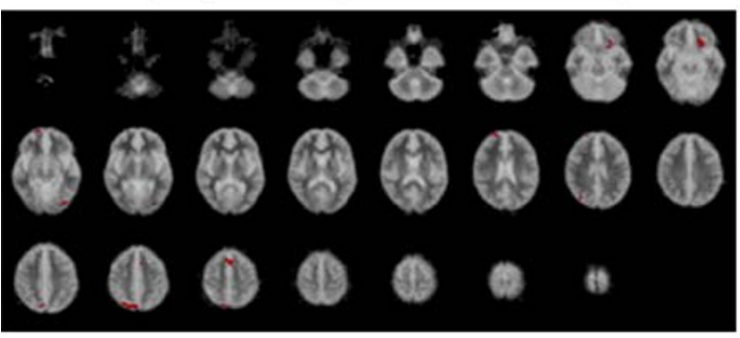

22q11DS: Age-related decrease

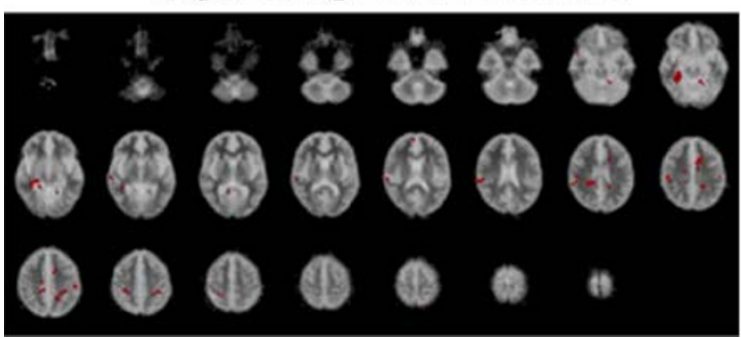

Control: Age-relatedincrease

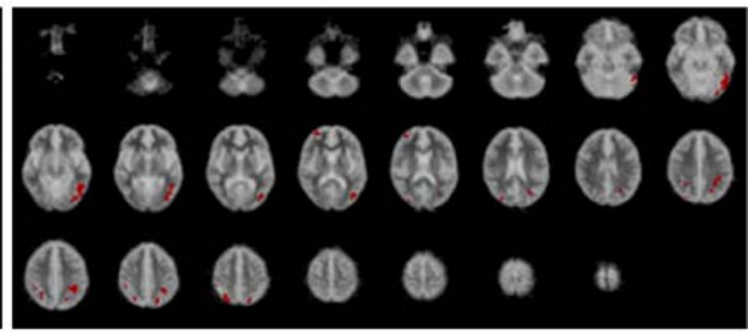

Control: Age-related decrease

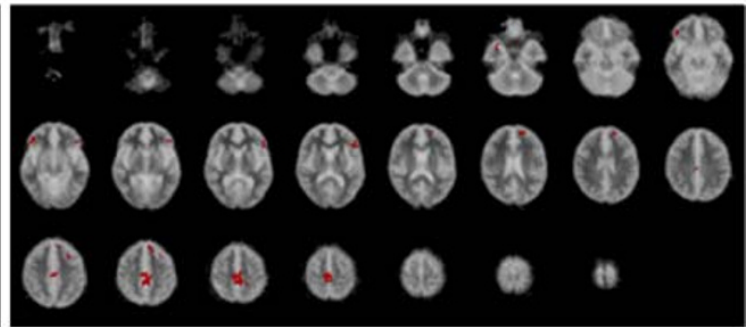

Fig. 5 Areas that showed age-related change in brain activation were observed (voxel $p=0.005$; cluster $p=0.01$ ) 
Table 4 Brain regions where age-related increase was observed in each group (voxel $p=0.005$, cluster $p=0.01$ )

\begin{tabular}{|c|c|c|c|c|c|c|c|c|c|c|c|}
\hline \multirow[t]{4}{*}{ Area } & \multirow[t]{4}{*}{ Brain region } & \multicolumn{10}{|c|}{ Age-related increase } \\
\hline & & \multicolumn{5}{|c|}{ 22q11DS } & \multicolumn{5}{|c|}{ Normal control } \\
\hline & & \multicolumn{3}{|c|}{ Coordinates } & \multirow[t]{2}{*}{$\mathrm{BA}$} & \multirow[t]{2}{*}{ Voxels $(n)$} & \multicolumn{3}{|c|}{ Coordinates } & \multirow[t]{2}{*}{$\mathrm{BA}$} & \multirow[t]{2}{*}{ Voxels $(n)$} \\
\hline & & $X$ & $Y$ & $Z$ & & & $X$ & $Y$ & $Z$ & & \\
\hline \multirow[t]{6}{*}{ Frontal } & \multicolumn{11}{|c|}{ Ventrolateral prefrontal cortex } \\
\hline & Left & -18 & 19 & -13 & 47 & 12 & & & & & \\
\hline & \multicolumn{11}{|c|}{ Middle frontal gyrus } \\
\hline & Right & & & & & & 32 & 56 & 9 & 10 & 7 \\
\hline & \multicolumn{6}{|c|}{ Superior frontal gyrus } & & & & & \\
\hline & Left & -4 & 11 & 48 & 6 & 11 & & & & & \\
\hline \multirow[t]{10}{*}{ Parietal } & \multicolumn{11}{|l|}{ Precuneus } \\
\hline & Left & & & & & & -18 & -63 & 42 & 7 & 6 \\
\hline & Right & 22 & -70 & 42 & 7 & 17 & & & & & \\
\hline & \multicolumn{11}{|c|}{ Inferior parietal lobule } \\
\hline & Left & & & & & & -32 & -44 & 37 & 40 & 14 \\
\hline & \multicolumn{11}{|c|}{ Superior parietal lobule } \\
\hline & Left & & & & & & -29 & -48 & 42 & 7 & 8 \\
\hline & Right & & & & & & 25 & -63 & 48 & 7 & 10 \\
\hline & \multicolumn{11}{|l|}{ Angular gyrus } \\
\hline & Right & & & & & & 29 & -59 & 37 & 39 & 5 \\
\hline \multirow[t]{4}{*}{ Temporal } & \multicolumn{11}{|c|}{ Fusiform gyrus } \\
\hline & Left & & & & & & -47 & -56 & -18 & 37 & 7 \\
\hline & \multicolumn{11}{|c|}{ Inferior temporal gyrus } \\
\hline & Left & & & & & & -51 & -52 & -13 & 20 & 24 \\
\hline \multirow[t]{4}{*}{ Occipital } & \multicolumn{11}{|c|}{ Inferior occipital gyrus } \\
\hline & Left & & & & & & -36 & -78 & -7 & 19 & 28 \\
\hline & \multicolumn{11}{|c|}{ Middle occipital gyrus } \\
\hline & Left & -29 & -81 & -7 & 18 & 5 & -40 & -74 & 9 & 19 & 8 \\
\hline \multirow[t]{2}{*}{ Limbic } & \multicolumn{11}{|c|}{ Posterior cingulate gyrus } \\
\hline & Left & & & & & & -25 & -67 & 20 & 31 & 5 \\
\hline
\end{tabular}

Minimum cluster size $=5$ voxels

Several prior studies have reported that people with 22q11DS have differences in the anatomy of frontal regions [44-48]. In addition, people with schizophrenia and non22q11DS 'high risk' groups are reported to have significant differences in activation of the DLPFC and parietal cortex [29]. Hence, we anticipated to find functional differences in these brain regions in people with 22q11DS (who are also at risk for developing schizophrenia). In agreement with Keshavan et al., [29], we found a significant difference in the activation of parietal regions, but not DLPFC. In an fMRI study on 22q11DS employing a task that requires frontal and parietal activation (i.e. arithmetic task), Eliez and colleagues [59] also found significant differences in the parietal, but no difference in the prefrontal region, suggesting that the findings from both studies are consistent.
Absence of group differences in PFC may simply mean that they could not be detected because of the relatively small sample size in the 22q11DS group $(n=8)$ with $1.5 \mathrm{~T}$ magnet in the current study, as well as in the study by Eliez et al. [59]. However, potential biological explanations include genetically determined differences in brain anatomy. Significant differences in the anatomy of various brain regions have been reported in young people with 22q11DS. For instance, recent imaging studies report that 22q11DS children and adolescents have a significantly reduced volume of grey matter in the parietal lobe, but a proportionally larger frontal lobe [44, 45]. Hence, reduced parietal activation may be explained by a regionally specific reduction in brain volume. In contrast, we may have found no difference in activation of DLPFC because the frontal structures may be relatively preserved, and hence, people 
Table 5 Brain regions where age-related decrease was observed in each group (voxel $p=0.005$; cluster $p=0.01$ )

\begin{tabular}{|c|c|c|c|c|c|c|c|c|c|c|c|}
\hline \multirow[t]{4}{*}{ Area } & \multirow[t]{4}{*}{ Brain area } & \multicolumn{10}{|c|}{ Age-related decrease } \\
\hline & & \multicolumn{5}{|c|}{$22 \mathrm{q} 11 \mathrm{DS}$} & \multicolumn{5}{|c|}{ Normal control } \\
\hline & & \multicolumn{3}{|c|}{ Coordinates } & \multirow[t]{2}{*}{ BA } & \multirow[t]{2}{*}{ Voxels $(n)$} & \multicolumn{3}{|c|}{ Coordinates } & \multirow[t]{2}{*}{ BA } & \multirow[t]{2}{*}{ Voxels $(n)$} \\
\hline & & $X$ & $Y$ & $Z$ & & & $X$ & $Y$ & $Z$ & & \\
\hline \multirow[t]{11}{*}{ Frontal } & \multicolumn{11}{|c|}{ Dorsolateral prefrontal cortex } \\
\hline & Left & & & & & & -14 & 48 & 20 & 9 & 6 \\
\hline & \multicolumn{11}{|c|}{ Venrtolateral prefrontal cortex } \\
\hline & Left & & & & & & -47 & 26 & 9 & 45 & 8 \\
\hline & Right & & & & & & 43 & 33 & -7 & 47 & 9 \\
\hline & \multicolumn{11}{|c|}{ Middle frontal gyrus } \\
\hline & Left & & & & & & -11 & 30 & 42 & 8 & 6 \\
\hline & \multirow{2}{*}{\multicolumn{4}{|c|}{ Right }} & & & 0 & -19 & 48 & 6 & 27 \\
\hline & & & & & & & 43 & 37 & -13 & 11 & 5 \\
\hline & \multicolumn{11}{|c|}{ Precentral lobule } \\
\hline & Right & & & & & & 11 & -30 & 53 & 6 & 18 \\
\hline \multirow[t]{5}{*}{ Parietal } & \multicolumn{11}{|l|}{ Precuneus } \\
\hline & Left & -14 & -48 & 37 & 7 & 6 & & & & & \\
\hline & Right & 25 & -37 & 26 & 31 & 11 & & & & & \\
\hline & \multicolumn{11}{|c|}{ Inferior parietal lobule } \\
\hline & Right & 47 & -30 & 31 & 40 & 6 & & & & & \\
\hline \multirow[t]{6}{*}{ Temporal } & \multicolumn{11}{|c|}{ Fusiform gyrus } \\
\hline & Right & 32 & -48 & -13 & 37 & 19 & & & & & \\
\hline & \multicolumn{11}{|c|}{ Middle temporal gyrus } \\
\hline & Right & & & & & & 36 & 0 & -24 & 21 & 5 \\
\hline & \multicolumn{6}{|c|}{ Superior temporal gyrus } & & & & & \\
\hline & Right & 61 & -30 & 20 & 42 & 8 & & & & & \\
\hline \multirow[t]{3}{*}{ Occipital } & \multicolumn{11}{|c|}{ Fusiform gyrus } \\
\hline & Left & -18 & -52 & -13 & 19 & 5 & & & & & \\
\hline & Right & 36 & -44 & -7 & 37 & 14 & & & & & \\
\hline \multirow[t]{3}{*}{ Limbic } & Cingulate $\mathrm{g}$ & & & & & & & & & & \\
\hline & Left & -4 & 7 & 31 & 24 & 10 & & & & & \\
\hline & Right & 18 & -33 & 37 & 31 & 5 & 4 & -33 & 42 & 31 & 25 \\
\hline
\end{tabular}

with 22q11DS become increasingly dependent on this region as previously suggested [59].

Alternatively, disruption in the 'connectivity' within the cortical network which underpins SWM, may explain our results. For example, in the healthy population DLPFC and parietal regions are activated during SWM tasks [60-62]. Also, Barnea-Goraly and colleagues [49] recently reported that people with 22q11DS have disrupted 'connectivity' (as measured using diffusion tensor imaging (DTI)) between frontal, parietal, and temporal regions. Thus, our finding of reduced activation in parietal regions may be explained by disrupted parietal 'connectivity'. In order to address this issue directly we plan further DTI studies in these subjects.
There is also a potential genetic explanation for the absence of significant differences in frontal activation between 22q11DS people and controls. Recent studies suggest that the gene coding for catechol-O-methyltransferase (COMT), which maps to the deleted region of $22 \mathrm{q} 11$ in $22 q 11 D S$, has neurobiological effects on the prefrontal cortex [63-70]. Egan and colleagues [70] reported that the Val (high-activity) COMT allele is associated with impaired prefrontal cortical function in both healthy populations and people with schizophrenia, while additional studies have reported that the low-activity Met allele is associated with superior prefrontal cortical function in both groups [69-71]. However, the effect of the low activity Met allele in people 
Table 6 Brain regions where significant differences in regression coefficient in age correlation was observed between 22q11DS and controls (voxel $p=0.05$; cluster $p=0.005$ )

\begin{tabular}{|c|c|c|c|c|c|c|c|c|c|c|c|}
\hline \multirow[t]{3}{*}{ Area } & \multirow[t]{3}{*}{ Brain region } & \multicolumn{5}{|c|}{ Controls $>22 q 11 D S$} & \multicolumn{5}{|c|}{ 22q11DS > controls } \\
\hline & & \multicolumn{3}{|c|}{ Coordinates } & \multirow[t]{2}{*}{ BA } & \multirow[t]{2}{*}{ Voxels $(n)$} & \multicolumn{3}{|c|}{ Coordinates } & \multirow[t]{2}{*}{ BA } & \multirow[t]{2}{*}{ Voxels $(n$} \\
\hline & & $X$ & $Y$ & $Z$ & & & $X$ & $Y$ & $Z$ & & \\
\hline \multirow[t]{5}{*}{ Frontal } & \multicolumn{11}{|c|}{ Inferior frontal gyrus } \\
\hline & Right & 7 & 15 & -18 & 11 & 9 & & & & & \\
\hline & Left & -22 & 33 & -18 & 11 & 9 & -51 & 0 & 20 & 44 & 6 \\
\hline & \multicolumn{11}{|c|}{ Middle frontal gyrus } \\
\hline & Right & 11 & 19 & -13 & 25 & 8 & & & & & \\
\hline \multirow[t]{4}{*}{ Parietal } & \multicolumn{11}{|c|}{ Inferior parietal lobule } \\
\hline & Right & 47 & -52 & 42 & 40 & 6 & & & & & \\
\hline & \multicolumn{11}{|c|}{ Postcentral gyrus } \\
\hline & Right & 51 & -19 & 26 & 2 & 10 & & & & & \\
\hline \multirow[t]{2}{*}{ Temporal } & \multicolumn{11}{|c|}{ Superior temporal gyrus } \\
\hline & Right & 58 & -26 & 15 & 42 & 19 & & & & & \\
\hline \multirow[t]{4}{*}{ Limbic } & \multicolumn{11}{|c|}{ Parahippocampal gyrus } \\
\hline & Right & 22 & -33 & -13 & 36 & 7 & & & & & \\
\hline & Hippocampus & & & & & & & & & & \\
\hline & Right & 29 & -26 & -7 & & 9 & & & & & \\
\hline \multirow[t]{9}{*}{ Sub-lobar } & Caudate & & & & & & & & & & \\
\hline & Right & 22 & -22 & 20 & & 9 & & & & & \\
\hline & Left & & & & & & -11 & 22 & 4 & & 5 \\
\hline & Thalamus & & & & & & & & & & \\
\hline & Left & -7 & -22 & 20 & & 7 & & & & & \\
\hline & Brainstem & & & & & & & & & & \\
\hline & Right & 11 & -11 & -7 & & 7 & & & & & \\
\hline & Cerebellum & & & & & & & & & & \\
\hline & Left & -4 & -30 & -13 & & 6 & & & & & \\
\hline
\end{tabular}

in 22q11DS remains unclear. There has been evidence that 22q11DS people with the Met allele perform significantly better [72] than those with the Val allele on executive function tasks which activate prefrontal regions (i.e. set-shifting, verbal fluency, attention, and working memory). Conversely, Gothelf and colleagues [73] reported that the low-activity Met allele is a risk factor for both the decline in prefrontal cortical volume and the consequent development of psychotic symptoms during adolescence in people with 22q11DS. Our current sample size is too small (22q11DS subjects with Met allele $=3$; those with Val allele $=5$ ) to examine the possible effect of the COMT Val ${ }^{108} /{ }^{158}$ Met polymorphism in 22q11DS, but we plan to address this issue in a future study.

Our study has some limitations. For example, the sample size was relatively small, which may account for the absence of group differences in the DLPFC. In addition, the controls were significantly more intelligent than people with 22q11DS, and the accuracy rate in the control group was approximately $20 \%$ higher than that in the 22q11DS group. Hence, it may be suggested that our results may be explained simply by differences in ability to perform the task, and/or it might have been better to have included an IQ matched non-deleted control group who were also matched on social and environmental factors. However, we compared people with 22q11DS to healthy controls (siblings of the 22q11DS subjects, where available) because our question was how brain activation in people with 22q11DS differs from the general population. Also, both groups activated brain regions which have been reported by others to be specifically implicated in SWM processing in both children and adults [32-35]. Hence, we were able to determine that our task was valid. In addition, the between-group differences remained even when we covaried for accuracy rate. Furthermore, unrelated learning disabled controls would most likely have comprised a heterogeneous population with a large variety of genetic and environmental/social differences. Hence, where possible we used sibling controls to account, as best we could, for environmental and social differences. Thus, the signifi- 
cantly higher activations in the healthy control group probably cannot be solely attributed to the better task performance or environmental and/or socio-economic factors.

In addition to the group differences in brain activation patterns, we also found preliminary evidence that people with 22q11DS may have differences in the developmental trajectories of brain function during SWM tasks. Within the healthy control group, an age-related increase in brain activations was observed largely in the posterior regions (e.g. bilateral superior parietal lobule, right angular gyrus, left inferior parietal lobule, precuneus, fusiform gyrus, inferior temporal gyrus, inferior-middle occipital gyrus) and a decrease mostly in the anterior regions (e.g. bilateral VLPFC, middle frontal gyri, left DLPFC, right precentral gyrus). In contrast, people with 22q11DS people tended to use more anterior (e.g. left VLPFC), and less posterior (e.g. bilateral precuneus, fusiform gyri, cingulate gyri), regions as they grow older. The age-related increases we found in the frontal and parietal cortical regions of controls are similar to findings from previous studies in normally developing children [32, 33]. Furthermore, a preliminary analysis of between-group differences in ageing indicated that there are significant differences between the developmental trajectories in the brain functions associated with SWM. Thus, our findings may provide preliminary evidence that, as people with 22q11DS develop, they do not undergo the normal age-related 'shift' to activating more posterior brain regions during SWM tasks, and instead continue to activate more anterior (frontal) systems. The biological basis of this putative difference in post-natal brain maturation is unknown.

In summary, we examined brain function in children with 22q11DS during a visuospatial working memory task. Both groups activated brain regions classically implicated in carrying out the task. However, healthy controls had significantly greater activation than children with 22q11DS of parietal and occipital regions. In addition, we found no significant between-group difference in activation of frontal regions. The neurobiological basis for our findings is unknown, but we suggest that it may reflect neurodevelopment differences in brain anatomy and connectivity. Further work is required, and in larger samples, to examine this issue.

Acknowledgements The authors would like to thank all the young people with and without 22q11DS who took part in the study, the 22q11 (UK) Support Group for their help and support in recruitment and the radiographers in the Department of Neuroimaging at the Maudsley Hospital for their expertise and work in acquiring the scans.

\section{Reference}

1. Scambler P, Carey A, Wuse R, Roach S, Dumanski J, Nordenskjold M, Williamson R. Microdeletions within 22q11 associated with sporadic and familial DiGeorge syndrome. Genomics 1991;10:201-6.
2. Gothelf D, Frisch A, Munitz H, Rockah R, Laufer N, Mozes T, Hermesh H, Weizman A, Frydman M, Gothelf D, Frisch A, Munitz H, Rockah R, Laufer N, Mozes T, Hermesh H, Weizman A, Frydman M. Clinical characteristics of schizophrenia associated with velo-cardio-facial syndrome. Schizophr Res 1999;35:105-12.

3. Shprintzen RJ, Goldberg RB, Lewin ML, Sidoti EJ, Berkman MD, Argamaso RV, Young D. A new syndrome involving cleft palate, cardiac anomalies typical facies and learning disabilities: velo-cardio-facial syndrome. Cleft Palate J 1978;15:15-62.

4. Murphy KC, Jones LA, Owen MJ, Murphy KC, Jones LA, Owen MJ. High rates of schizophrenia in adults with velo-cardio-facial syndrome. Arch Gen Psychiatry 1999;56:940-5.

5. Papolos DF, Faedda GL, Veit S, Goldberg R, Morrow B, Kucherlapati R, Shprintzen RJ, Papolos DF, Faedda GL, Veit S, Goldberg R, Morrow B, Kucherlapati R, Shprintzen RJ. Bipolar spectrum disorders in patients diagnosed with velo-cardio-facial syndrome: does a hemizygous deletion of chromosome $22 \mathrm{q} 11$ result in bipolar affective disorder? Am J Psychiatr 1996;153:1541-7.

6. Pulver AE, Nestadt G, Goldberg R, Shprintzen RJ. Psychotic illness in patients diagnosed with velo-cardio-facial syndrome and their relatives. J Nerv Ment Dis 1994;182:476-8.

7. Shprintzen RJ, Goldberg R, Golding-Kushner KJ, Marion RW, Shprintzen RJ, Goldberg R, Golding-Kushner KJ, Marion RW. Late-onset psychosis in the velo-cardio-facial syndrome. Am J Med Genet 1992;42:141-2.

8. Henry JC, van Amelsvoort T, Morris RG, Owen MJ, Murphy DG, Murphy KC. An investigation of the neuropsychological profile in adults with velo-cardio-facial syndrome (VCFS). Neuropsychologia 2002;40:471-8.

9. Moss EM, Batshaw ML, Solot CB, Gerdes M, McDonaldMcGinn DM, Driscoll DA, Emanuel BS, Zackai EH, Wang PP, Moss EM, Batshaw ML, Solot CB, Gerdes M, McDonaldMcGinn DM, Driscoll DA, Emanuel BS, Zackai EH, Wang PP. Psychoeducational profile of the 22q11.2 microdeletion: a complex pattern. J Pediatr 1999;134:193-8.

10. Swillen A, Devriendt K, Legius E, Eyskens B, Dumoulin M, Gewillig M, Fryns JP. Intelligence and psychosocial adjustment in velocardiofacial syndrome: a study of 37 children and adolescents with VCFS. J Med Genet 1997;34:453-8.

11. Swillen A, Vogels A, Devriendt K, Fryns JP. Chromosome 22q11 deletion syndrome: update and review of the clinical features, cognitive-behavioral spectrum, and psychiatric complications. Am J Med Genet 2000;97:128-35.

12. van Amelsvoort T, Henry J, Morris R, Owen M, Linszen D, Murphy K, Murphy D, van Amelsvoort T, Henry J, Morris R, Owen M, Linszen D, Murphy K, Murphy D. Cognitive deficits associated with schizophrenia in velo-cardio-facial syndrome. Schizophr Res 2004;70:223-32.

13. Lewandowski KE, Shashi V, Berry PM, Kwapil TR. Schizophrenic-like neurocognitive deficits in children and adolescents with 22q11 deletion syndrome. Part B, neuropsychiatric genetics: the official publication of the International Society of Psychiatric Genetics. Am J Med Genet 2007;144:27-36.

14. Murphy KC. Schizophrenia and velo-cardio-facial syndrome. Lancet 2002;359(9304):426-30.

15. Smith CW, Park S, Cornblatt B, Smith CW, Park S, Cornblatt B. Spatial working memory deficits in adolescents at clinical high risk for schizophrenia. Schizophr Res 2006;81:211-5.

16. Fleming K, Goldberg TE, Binks S, Randolph C, Gold JM, Weinberger DR. Visuospatial working memory in patients with schizophrenia. Biol Psychiatry 1997;41:43-9.

17. Goldman-Rakic PS. The physiological approach: functional architecture of working memory and disordered cognition in schizophrenia. Biol Psychiatry 1999;46:650-61.

18. Harvey PD, Powchik P, Mohs RC, Davidson M. Memory functions in geriatric chronic schizophrenic patients: a neuropsy- 
chological study. Journal of Neuropsychiatry \& Clinical Neurosciences 1995;7:207-12.

19. Keefe RS, Lees-Roitman SE, Dupre RL. Performance of patients with schizophrenia on a pen and paper visuospatial working memory task with short delay. Schizophr Res 1997;26:9-14.

20. Kindermann SS, Brown GG, Zorrilla LE, Olsen RK, Jeste DV. Spatial working memory among middle-aged and older patients with schizophrenia and volunteers using fMRI. Schizophr Res 2004;68:203-16.

21. Park S, Holzman PS. Schizophrenics show spatial working memory deficits. Arch Gen Psychiatry 1992;49:975-82.

22. Park S, Puschel J, Sauter BH, Rentsch M, Hell D. Spatial working memory deficits and clinical symptoms in schizophrenia: a 4month follow-up study. Biol Psychiatry 1999;46:392-400.

23. Salame P, Danion JM, Peretti S, Cuervo C. The state of functioning of working memory in schizophrenia. Schizophr Res 1998;30:11-29.

24. Thermenos HW, Goldstein JM, Buka SL, Poldrack RA, Koch JK, Tsuang MT, Seidman LJ. The effect of working memory performance on functional MRI in schizophrenia. Schizophr Res 2005;74:179-94.

25. Lee J, Folley BS, Gore J, Park S. Origins of spatial working memory deficits in schizophrenia: an event-related FMRI and near-infrared spectroscopy study. PLoS ONE 2008;3:e1760.

26. Glahn DC, Therman S, Manninen M, Huttunen M, Kaprio J, Lonnqvist J, Cannon TD. Spatial working memory as an endophenotype for schizophrenia. Biol Psychiatry 2003;53:624-6.

27. Saperstein AM, Fuller RL, Avila MT, Adami H, McMahon RP, Thaker GK, Gold JM. Spatial working memory as a cognitive endophenotype of schizophrenia: assessing risk for pathophysiological dysfunction. Schizophr Bull 2006;32:498-506.

28. Cannon TD, Huttunen MO, Lonnqvist J, Tuulio-Henriksson A, Pirkola T, Glahn D, Finkelstein J, Hietanen M, Kaprio J, Koskenvuo M. The inheritance of neuropsychological dysfunction in twins discordant for schizophrenia. Am J Hum Genet 2000;67:369-82.

29. Keshavan MS, Diwadkar VA, Spencer SM, Harenski KA, Luna B, Sweeney JA. A preliminary functional magnetic resonance imaging study in offspring of schizophrenic parents. Prog Neuropsychopharmacol Biol Psychiatry 2002;26:1143-9.

30. Wood SJ, Pantelis C, Proffitt T, Phillips LJ, Stuart GW, Buchanan JA, Mahony K, Brewer W, Smith DJ, McGorry PD, Wood SJ, Pantelis C, Proffitt T, Phillips LJ, Stuart GW, Buchanan JA, Mahony K, Brewer W, Smith DJ, McGorry PD. Spatial working memory ability is a marker of risk-for-psychosis. Psychol Med 2003;33:1239-47.

31. Brewer WJ, Wood SJ, Phillips LJ, Francey SM, Pantelis C, Yung AR, Cornblatt B, McGorry PD. Generalized and specific cognitive performance in clinical high-risk cohorts: a review highlighting potential vulnerability markers for psychosis. Schizophr Bull 2006;32:538-55.

32. Klingberg T, Forssberg H, Westerberg H. Increased brain activity in frontal and parietal cortex underlies the development of visuospatial working memory capacity during childhood. J Cogn Neurosci 2002; 14:1-10.

33. Kwon H, Reiss AL, Menon V. Neural basis of protracted developmental changes in visuo-spatial working memory. Proc Natl Acad Sci USA 2002;99:13336-41.

34. Nelson CA, Monk CS, Lin J, Carver LJ, Thomas KM, Truwit CL. Functional neuroanatomy of spatial working memory in children. Dev Psychol 2000;36:109-16.

35. Thomas KM, King SW, Franzen PL, Welsh TF, Berkowitz AL, Noll DC, Birmaher V, Casey BJ. A developmental functional MRI study of spatial working memory. Neuroimage 1999;10:327-38.

36. Rypma B, D'Esposito M. Isolating the neural mechanisms of agerelated changes in human working memory. Nat Neurosci 2000;3:509-15.
37. Lenroot RK, Giedd JN. Brain development in children and adolescents: insights from anatomical magnetic resonance imaging. Neurosci Biobehav Rev 2006;30:718-29.

38. Berman KF, Zec RF, Weinberger DR. Physiologic dysfunction of dorsolateral prefrontal cortex in schizophrenia. II. Role of neuroleptic treatment, attention, and mental effort. Arch Gen Psychiatry 1986;43:126-35.

39. Callicott JH, Ramsey NF, Tallent K, Bertolino A, Knable MB, Coppola R, Goldberg T, van Gelderen P, Mattay VS, Frank JA, Moonen CT, Weinberger DR. Functional magnetic resonance imaging brain mapping in psychiatry: methodological issues illustrated in a study of working memory in schizophrenia. Neuropsychopharmacology 1998;18:186-96.

40. Stevens AA, Goldman-Rakic PS, Gore JC, Fulbright RK, Wexler BE. Cortical dysfunction in schizophrenia during auditory word and tone working memory demonstrated by functional magnetic resonance imaging. Arch Gen Psychiatry 1998;55:1097-103.

41. Manoach DS, Gollub RL, Benson ES, Searl MM, Goff DC, Halpern E, Saper CB, Rauch SL. Schizophrenic subjects show aberrant fMRI activation of dorsolateral prefrontal cortex and basal ganglia during working memory performance. Biol Psychiatry 2000;48:199-09.

42. Walter H, Wunderlich AP, Blankenhorn M, Schafer S, Tomczak R, Spitzer M, Gron G. No hypofrontality, but absence of prefrontal lateralization comparing verbal and spatial working memory in schizophrenia. Schizophr Res 2003;61:175-84.

43. Koenigsberg HW, Buchsbaum MS, Buchsbaum BR, Schneiderman JS, Tang CY, New A, Goodman M, Siever LJ. Functional MRI of visuospatial working memory in schizotypal personality disorder: a region-of-interest analysis. Psychol Med 2005;35:1019-30.

44. Eliez S, Schmitt JE, White CD, Reiss AL. Children and Adolescents with velo-cardio-facial syndrome: a volumetric MRI study. Am J Psych 2000;157:409-15.

45. Kates WR, Burnette CP, Jabs EW, Rutberg J, Murphy AM, Grados M, Geraghty M, Kaufmann WE, Pearlson GD. Regional cortical white matter reductions in velocardiofacial syndrome: a volumetric MRI analysis. Biol Psychiatry 2001;49:677-84.

46. van Amelsvoort T, Daly E, Robertson D, Suckling J, Ng V, Critchley H, Owen MJ, Henry J, Murphy KC, Murphy DGM. Structural brain abnormalities associated with deletion at chromosome 22q11: quantitative neuroimaging study of adults with velocardio-facial syndrome. Br J Psychiatry 2001;178:412-9.

47. Campbell LE, Daly E, Toal F, Stevens A, Azuma R, Catani M, Ng V, van Amelsvoort T, Chitnis X, Cutter W, Murphy DG, Murphy KC. Brain and behaviour in children with 22q11.2 deletion syndrome: a volumetric and voxel-based morphometry MRI study. Brain 2006;129:1218-28.

48. Kates WR, Burnette CP, Bessette BA, Folley BS, Strunge L, Jabs EW, Pearlson GD, Kates WR, Burnette CP, Bessette BA, Folley BS, Strunge L, Jabs EW, Pearlson GD. Frontal and caudate alterations in velocardiofacial syndrome (deletion at chromosome 22q11.2). J Child Neurol 2004;19:337-42.

49. Barnea-Goraly N, Eliez S, Menon V, Bammer R, Reiss AL. Arithmetic ability and parietal alterations: a diffusion tensor imaging study in velocardiofacial syndrome. Cogn Brain Res 2005;25:735-40.

50. Simon TJ, Ding L, Bish JP, McDonald-McGinn DM, Zackai EH, Gee J, Simon TJ, Ding L, Bish JP, McDonald-McGinn DM, Zackai $\mathrm{EH}$, Gee J. Volumetric, connective, and morphologic changes in the brains of children with chromosome 22q11.2 deletion syndrome: an integrative study. Neuroimage 2005;25:169-80.

51. Wechsler D. Wechsler Intelligence Scales for children-third edition. San Antonio, TX: The Psychological Corporation; 1991.

52. Ogawa S, Lee TM, Kay AR, Tank DW. Brain magnetic resonance imaging with contrast dependent on blood oxygenation. Proc Natl Acad Sci USA 1990;87:9868-72. 
53. Brammer MJ, Bullmore ET, Simmons A, Williams SC, Grasby PM, Howard RJ, Woodruff PW, Rabe-Hesketh S. Generic brain activation mapping in functional magnetic resonance imaging: a nonparametric approach. Magn Reson Imaging 1997;15:76370.

54. Bullmore ET, Brammer MJ, Rabe-Hesketh S, Curtis VA, Morris RG, Williams SC, Sharma T, McGuire PK. Methods for diagnosis and treatment of stimulus-correlated motion in generic brain activation studies using fMRI. Hum Brain Mapp 1999;7:38-48.

55. Friman $\mathrm{O}$, Borga $\mathrm{M}$, Lundberg $\mathrm{P}$, Knutsson $\mathrm{H}$. Adaptive analysis of fMRI data. Neuroimage 2003;19(3):837-45.

56. Bullmore E, Long C, Suckling J, Fadili J, Calvert G, Zelaya F, Carpenter TA, Brammer M. Colored noise and computational inference in neurophysiological (fMRI) time series analysis: resampling methods in time and wavelet domains. Hum Brain Mapp 2001;12(2):61-78.

57. Bullmore ET, Suckling J, Overmeyer S, Rabe-Hesketh S, Taylor E, Brammer MJ. Global, voxel, and cluster tests, by theory and permutation, for a difference between two groups of structural MR images of the brain. IEEE Trans Med Imag 1999;18:32-42.

58. Talairach JTP. Co-planar stereotaxic atlas of the human brain. New York: Thieme; 1988.

59. Eliez S, Blasey C, Menon V, White C, Schmitt J, Reiss A. Functional brain imaging study of mathematical reasoning abilities in velocardiofacial syndrome (del22q11.2). Genet Med 2001;3:49-55.

60. Awh E, Jonides J. Spatial working memory and spatial selective attention. In: Parasuraman R, editor. The attentive brain. Cambridge, MA: The MIT; 1998. p. 353-80. xii, 577.

61. Diwadkar VA, Carpenter PA, Just MA. Collaborative activity between parietal and dorso-lateral prefrontal cortex in dynamic spatial working memory revealed by fMRI. Neuroimage 2000;12:85-99.

62. Ungerleider LG, Courtney SM, Haxby JV. A neural system for human visual working memory. Proc Natl Acad Sci USA 1998;95:883-90.

63. Caldu X, Vendrell P, Bartres-Faz D, Clemente I, Bargallo N, Jurado MA, Serra-Grabulosa JM, Junque C. Impact of the COMT Val108/158 Met and DAT genotypes on prefrontal function in healthy subjects. Neuroimage 2007;37:1437-44.

64. McIntosh AM, Baig BJ, Hall J, Job D, Whalley HC, Lymer GKS, Moorhead TWJ, Owens DGC, Miller P, Porteous D, Lawrie SM, Johnstone EC. Relationship of catechol-O-methyltransferase variants to brain structure and function in a population at high risk of psychosis. Biol Psychiatry 2007;61:1127-34.
65. Ehlis A-C, Reif A, Herrmann MJ, Lesch K-P, Fallgatter AJ. Impact of catechol-O-methyltransferase on prefrontal brain functioning in schizophrenia spectrum disorders. Neuropsychopharmacology 2007;32:162-70.

66. Bertolino A, Rubino V, Sambataro F, Blasi G, Latorre V, Fazio L, Caforio G, Petruzzella V, Kolachana B, Hariri A, MeyerLindenberg A, Nardini M, Weinberger DR, Scarabino T. Prefrontal-hippocampal coupling during memory processing is modulated by COMT val158met genotype. Biol Psychiatry 2006;60:1250-8.

67. Blasi G, Mattay VS, Bertolino A, Elvevag B, Callicott JH, Das S, Kolachana BS, Egan MF, Goldberg TE, Weinberger DR. Effect of catechol-O-methyltransferase val158met genotype on attentional control. J Neurosci 2005;25:5038-45.

68. Goldberg TE, Egan MF, Gscheidle T, Coppola R, Weickert T, Kolachana BS, Goldman D, Weinberger DR. Executive subprocesses in working memory: relationship to catechol-Omethyltransferase Val158Met genotype and schizophrenia. Arch Gen Psychiatry 2003;60:889-96.

69. Malhotra AK, Kestler LJ, Mazzanti C, Bates JA, Goldberg T, Goldman D. A functional polymorphism in the COMT gene and performance on a test of prefrontal cognition. Am J Psych 2002;159:652-4.

70. Egan MF, Goldberg TE, Kolachana BS, Callicott JH, Mazzanti CM, Straub RE, Goldman D, Weinberger DR. Effect of COMT Val108/158 Met genotype on frontal lobe function and risk for schizophrenia. Proc Natl Acad Sci USA 2001;98:6917-22.

71. Bilder RM, Volavka J, Czobor P, Malhotra AK, Kennedy JL, Ni X, Goldman RS, Hoptman MJ, Sheitman B, Lindenmayer J-P, Citrome L, McEvoy JP, Kunz M, Chakos M, Cooper TB, Lieberman JA. Neurocognitive correlates of the COMT Val(158)Met polymorphism in chronic schizophrenia. Biol Psychiatry 2002;52:701-7.

72. Bearden CE, Jawad AF, Lynch DR, Sokol S, Kanes SJ, McDonald-McGinn DM, Saitta SC, Harris SE, Moss E, Wang PP, Zackai E, Emanuel BS, Simon TJ, Bearden CE, Jawad AF, Lynch DR, Sokol S, Kanes SJ, McDonald-McGinn DM, Saitta SC, Harris SE, Moss E, Wang PP, Zackai E, Emanuel BS, Simon TJ. Effects of a functional COMT polymorphism on prefrontal cognitive function in patients with 22q11.2 deletion syndrome. Am J Psych 2004;161:1700-2.

73. Gothelf D, Eliez S, Thompson T, Hinard C, Penniman L, Feinstein C, Kwon H, Jin S, Jo B, Antonarakis SE, Morris MA, Reiss AL, Gothelf D, Eliez S, Thompson T, Hinard C, Penniman L, Feinstein C, Kwon H, Jin S, Jo B, Antonarakis SE, Morris MA, Reiss AL. COMT genotype predicts longitudinal cognitive decline and psychosis in 22q11.2 deletion syndrome. Nat Neurosci 2005;8:1500-2. 